\title{
How Missing Discharge Diagnosis Data in Syndromic Surveillance Leads to Coverage Gaps
}

\author{
Kayley Dotson* and Mandy Billman \\ Epidemiology Resource Center, Indiana State Department of Health, Indianapolis, IN, USA
}

\section{Objective}

To identify surveillance coverage gaps in emergency department (ED) and urgent care facility data due to missing discharge diagnoses.

\section{Introduction}

Indiana utilizes the Electronic Surveillance System for the Early Notification of Community-Based Epidemics (ESSENCE) to collect and analyze data from participating hospital emergency departments. This real-time collection of health related data is used to identify disease clusters and unusual disease occurrences. By Administrative Code, the Indiana State Department of Health (ISDH) requires electronic submission of chief complaints from patient visits to EDs. Submission of discharge diagnosis is not required by Indiana Administrative Code, leaving coverage gaps. Our goal was to identify which areas in the state may see under reporting or incomplete surveillance due to the lack of the discharge diagnosis field.

\section{Methods}

Emergency department data were collected from Indiana hospitals and urgent care clinics via ESSENCE. Discharge diagnosis was analyzed by submitting facility to determine percent completeness of visits. A descriptive analysis was conducted to identify the distribution of facilities that provide discharge diagnosis. A random sample of 20 days of data were extracted from visits that occurred between January 1,2017 and September 6, 2017.

\section{Results}

A random sample of $179,039(8 \%)$ ED entries from a total of $2,220,021$ were analyzed from 121 reporting facilities. Of the sample entries, 102,483 (57.24\%) were missing the discharge diagnosis field. Over $40(36 \%)$ facilities were missing more than $90 \%$ of discharge diagnosis data. Facilities are more likely to be missing $>90 \%$ or $<19 \%$ of discharge diagnoses, rather than between those points.

Comparing the percent of syndromic surveillance entries missing discharge diagnosis across facilities reveals large variability. For example, some facilities provide no discharge diagnoses while other facilities provide $100 \%$. The number of facilities missing $100 \%$ of discharge diagnoses $(n=19)$ is 6.3 times that of the facilities that are missing $0 \%(n=3)$.

The largest coverage gap was identified in Public Health Preparedness District (PHPD) ${ }^{1}$ three $(93.16 \%)$, with districts five (64.97\%), seven (61.94\%), and four (61.34\%) making up the lowest reporting districts. See Table 2 and Figure $1^{2}$ for percent missing by district and geographic distribution. PHPD three and five contain a large proportion (38\%) of the sample population ED visits which results in a coverage gap in the most populated areas of the state.

\section{Conclusions}

Querying ESSENCE via chief complaint data is useful for realtime surveillance, but is more informative when discharge diagnoses are available. Indiana does not require facilities to report discharge diagnosis, but regulatory changes are being proposed that would require submission of discharge diagnosis data to ISDH. The addition of discharge diagnose is aimed to improve the completeness of disease clusters and unusual disease occurrence surveillance data.
Table 1. Emergency department facilities by percent (\%) missing discharge diagnosis.

\begin{tabular}{|c|c|}
\hline Percent $(\%)$ missing discharge diagnosis & Number of emergency department facilities \\
\hline 0 & 3 \\
\hline $0.01-9$ & 15 \\
\hline $10-19$ & 11 \\
\hline $20-29$ & 9 \\
\hline $30-39$ & 10 \\
\hline $40-49$ & 11 \\
\hline $50-59$ & 3 \\
\hline $60-69$ & 6 \\
\hline $70-79$ & 6 \\
\hline $80-89$ & 4 \\
\hline $90-99$ & 25 \\
\hline 100 & 19 \\
\hline
\end{tabular}

Table 2. Percent (\%) missing discharge diagnosis by Public Health Preparedness District (PHPD).

\begin{tabular}{|c|c|}
\hline PHPD & Average percent (\%) missing \\
\hline District 1 & 34.12 \\
\hline District 2 & 56.70 \\
\hline District 3 & 93.16 \\
\hline District 4 & 61.34 \\
\hline District 5 & 64.97 \\
\hline District 6 & 49.77 \\
\hline District 7 & 61.94 \\
\hline District 8 & 47.52 \\
\hline District 9 & 50.86 \\
\hline District 10 & 41.55 \\
\hline Indiana Average & 57.24 \\
\hline
\end{tabular}

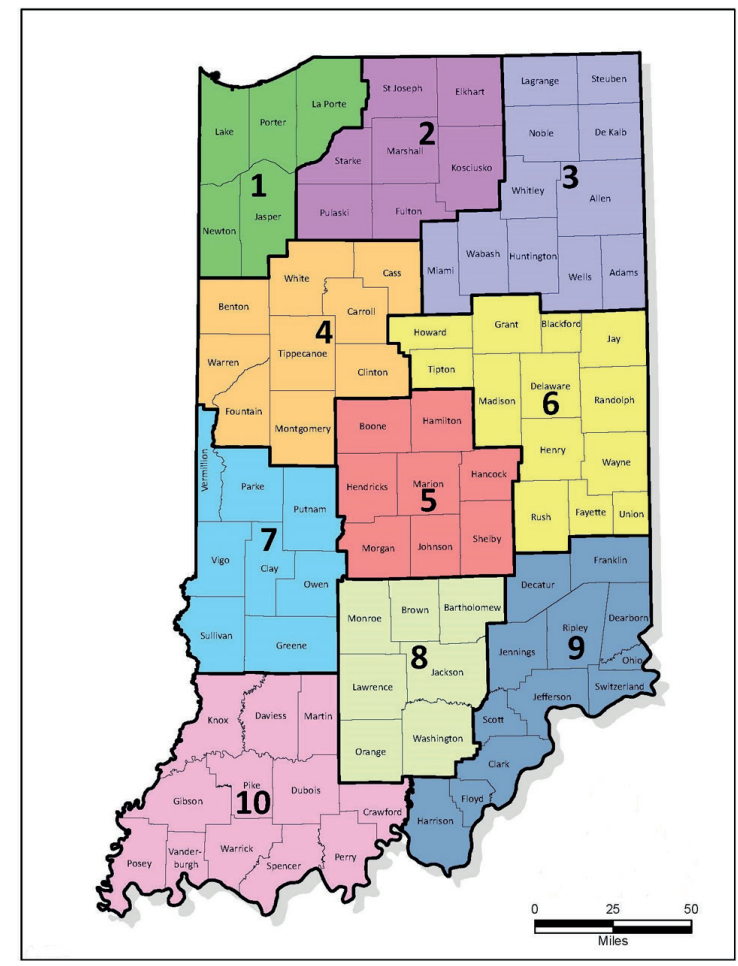

Figure 1. Indiana Public Health Preparedness Districts 


\section{ISDS 2018 Conference Abstracts}

Keywords

Syndromic surveillance; discharge diagnosis; outbreak coverage

\section{Acknowledgments}

The authors gratefully acknowledge Ann Kayser and Noah Zarr for their support and contributions to the project.

\section{References}

1. Preparedness Districts [Internet]. Indianapolis (IN): Indiana State Department of Health, Public Health Preparedness; 2017 [Cited 2017 Sept 20]. Available from: https://www.in.gov/isdh/17944.htm.

\section{*Kayley Dotson}

E-mail: kdotson0914@gmail.com 